\title{
A Father/Son Sitdown: Howard and Steven Aldrich
}

\author{
Howard E. Aldrich (University of North Carolina at Chapel Hill)
}

KEYWORDS: Telecommunications \& Internet, Banking, Finance, Insurance, Information, Software, Data, Entrepreneurship, Innovation, Management, Organization, Information Technology, Venture Capital, Leadership, Strategy, Technology Commercialization.

More than 20 years ago, Steven Aldrich showed the Mosaic Browser to his father, noted entrepreneurship professor Howard Aldrich. It was a time when Steven was imagining a future in helping technology companies grow. Fast forward -- through Steven's first business selling summer storage for college students, his years at Stanford Business School, his online insurance company that was bought by Intuit after some nail-biting moments, and other solo ventures -- and Steven today is Chief Product Officer at GoDaddy. He has learned much about the challenges not only of starting a new business, but also managing it when it becomes bigger. In this interview with his father, Steven talks about his experiences and shares his advice to new entrepreneurs. The key takeaways: Don't be afraid to start before you are ready. And no matter what happens to your venture, you can learn and get better. 